\title{
Extensive study on hydrodynamics and heat transfer of laminar mixed convection
}

\author{
De-Yi Shang', Liang-Cai Zhong ${ }^{2}$ \\ ${ }^{1} 136$ Ingersoll Cres., Ottawa, ON, Canada K2T 3W9 \\ ${ }^{2}$ Department of Ferrous Metallurgy, Northeastern University, Shenyang 110004, China \\ Email address: \\ deyishang@yahoo.ca (De-Yi Shang)
}

\section{To cite this article:}

De-Yi Shang, Liang-Cai Zhong. Extensive Study on Hydrodynamics and Heat Transfer of Laminar Mixed Convection. Science Journal of Energy Engineering. Special Issue: Convection Heat and Mass Transfer Vol. 3, No. 3-1, 2015, pp. 8-17.

doi: 10.11648/j.sjee.s.2015030301.12

\begin{abstract}
Through extensive study on hydrodynamics and heat transfer, calculation correlations of heat transfer for laminar free/forced mixed convection on a vertical flat plate is obtained. It contains the following three research investigations: (i) local-similarity analysis and transformation based on our developed new similarity analysis method replacing the traditional Falkner-Skan type transformation; (ii) New governing local-similarity mathematical model, which is first applied in study of laminar free/forced mixed convection. It is more conveniently obtained and applied compared with that based on the FalknerSkan type transformation for investigation of free/forced mixed convection; and (iii) New correlations on heat transfer of laminar free/forced mixed convection. They have wide coverage of Prandtl number and mixed convection parameter, and are suitable for all gases and important liquids including water for laminar free/forced mixed convection. The reported heat transfer correlations are so reliably because they are produced based on combination of theoretical analysis equations with the correlations formulated rigorously according to system of groups on accurate numerical solutions.
\end{abstract}

Keywords: Hydrodynamics, Heat transfer, Local-similarity transformation, Laminar mixed convection, Heat transfer correlations, New similarity method, Core similarity variables

\section{Introduction}

Free/forced mixed convective (for simplicity, hereinafter referred to as mixed convection) is a coupled phenomenon of free and forced convections, having even much challenging and wide practical application background. So far, the history of its study has over a half century. In the books of Gebhart et al. [1], Bejan [2] and Pop and Ingham [3] the detailed reviews were done for concerning the boundary layer equations on mixed convective flow. Meanwhile, numerous academic papers were published for investigation of mixed convection, and only some of them, such as refs. [4 -24], are listed here for saving space. In these investigations, the combined convection in a boundary layer flow was analysed. The studies, such as those of Acrivos [4], Sparrow et al. [5], Szewcyk [6], Chen [15], Merkin et al. [18], Ali [21], and Aydin el al. [22] investigated the effect of the parameter $G r_{x} / R e_{x}^{2}$ on mixed convection. In most of these analyses, the stream function was induced based on the Falkner-Skan type transformation for obtaining the governing partial differential equations. Additionally, in some of the studies, the finite difference method such as in works of Oosthuizen [7], Chen [15], Hossain [17], Sami [20] and Anilkumar [24], the perturbation method such as in work of Yao [12] and Hossain [17], and the finite element method such as in work of Rana [23] were applied. The studies are also often found for free-forced mixed boundary layer flow in a porous medium, such as those presented by Cheng [8], Hsieh et al. [13] and Harris et al.[16], which broadened the range of application of mixed convection. Raju [10], Chen [11], Harris et al. [16], and Merkin et al. [18] studied the boundary-layer flow of mixed convection with the buoyancy forces either adding (positive flow) or opposing (negative flow) type to the bulk flow. Some of studies, such as those by Raju [10], Chen [11], and Aydin el al. [22] developed the expressions correlating Nusselt number in terms of the related parameters for further application of heat transfer.

For obtaining the correlations for heat transfer application of mixed convection, this present work will use three new approached. They are (i) local-similarity analysis and transformation based on our developed new similarity 
analysis method replacing the traditional Falkner-Skan type transformation; (ii) New governing local-similarity mathematical model, which is first applied in study of laminar free/forced mixed convection. It is more conveniently obtained and applied compared with that based on the Falkner-Skan type transformation for investigation of free/forced mixed convection; and (iii) New correlations on heat transfer of laminar free/forced mixed convection. They have wide coverage of Prandtl number and mixed convection parameter, and are suitable for all gases and important liquids including water for laminar free/forced mixed convection. We expect these developments will be in favor of meeting the challenges encountered for deep investigation of free/forced mixed convection.

\section{Basic Conservation Equations}

\subsection{Governing Partial Differential Equations}

In Fig. 1 the physical model and co-ordinate system of boundary layer with two-dimensional mixed convection are shown schematically. A flat plate is vertically located in parallel fluid flow with its main stream velocity $w_{x, \infty}$. The plate surface temperature is $t_{w}$ and the fluid bulk temperature is $t_{\infty}$. Then, a coupled velocity boundary layer is produced near the plate. If the value of $t_{w}$ is different from that of $t_{\infty}$, a temperature boundary layer will occur near the plate. Then, Eqs. (1) to (3) can be taken as follows for governing partial differential equations of the laminar free/forced mixed convection boundary layer without consideration of variable physical properties and viscous thermal dissipation:

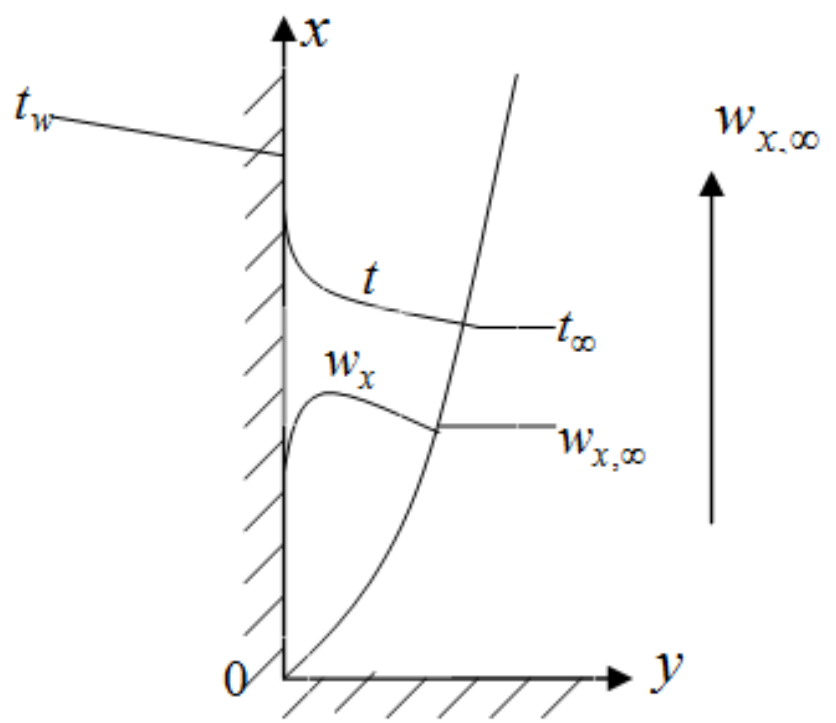

Fig. 1. Physical model and coordinate system of boundary layer for laminar freelforced convection on a vertical flat plate

$$
\frac{\partial}{\partial x}\left(w_{x}\right)+\frac{\partial}{\partial y}\left(w_{y}\right)=0
$$

$$
\begin{gathered}
w_{x} \frac{\partial w_{x}}{\partial x}+w_{y} \frac{\partial w_{x}}{\partial y}=v_{f} \frac{\partial^{2} w_{x}}{\partial y^{2}}+g \beta\left(t-t_{\infty}\right) \\
w_{x} \frac{\partial t}{\partial x}+w_{y} \frac{\partial t}{\partial y}=\frac{v_{f}}{\operatorname{Pr}_{f}} \frac{\partial^{2} t}{\partial y^{2}}
\end{gathered}
$$

with the boundary condition equations

$$
\begin{gathered}
\mathrm{y}=0: w_{x}=0, \mathrm{w}_{\mathrm{y}}=0, t=t_{w} \\
\mathrm{y} \rightarrow \infty: w_{x}=w_{x, \infty}(\text { constant }), t=t_{\infty}
\end{gathered}
$$

where Eqs. (1) to (3) are continuity, momentum, and energy equations respectively, and the subscript $f$ of the physical property variables denotes that the related reference temperature is the average temperature $t_{f}=\frac{t_{w}+t_{\infty}}{2}$.

\section{Supposed Similarity Variables for Local-Similarity Transformation}

For laminar mixed convection, full similarity transformation of the governing partial differential equations can not be achieved, and the local-similarity transformation should be done. The next work is further analysis for supposed similarity variables. We find that there are two key issues for mixed convection. They are: (i) The governing equations are attributed to free convection form; (ii) The boundary conditions belong to forced convection form. In this case, we select the core similarity variables with forced convection form for coincidence to the boundary conditions. Consulting our new similarity analysis method reported in refs. [25], the following equations with the core similarity variables are given for the similarity transformation of the velocity field:

$$
\begin{gathered}
w_{x}=w_{x, \infty} W_{x}(\eta, x) \\
w_{y}=w_{x, \infty}\left(\frac{1}{2} \operatorname{Re}_{x}\right)^{-1 / 2} W_{y}(\eta, x) \\
\theta(\eta, x)=\frac{t-t_{\infty}}{t_{w}-t_{\infty}}
\end{gathered}
$$

Here, $W_{x}(\eta, x)$ and $W_{y}(\eta, x)$ are the core similarity variables for similarity transformation of the velocity field respectively in $\mathrm{x}$ and $\mathrm{y}$ directions, and $\theta(\eta, x)$ is supposed as the dimensionless temperature variable. While, the dimensionless coordinate variable $\eta$ and the local Reynolds number $\mathrm{Re}_{x, f}$ are respectively described as

$$
\operatorname{Re}_{x, f}=\frac{w_{x, \infty} x}{v_{f}}
$$




$$
\eta=\frac{y}{x}\left(\frac{1}{2} \operatorname{Re}_{x, f}\right)^{1 / 2}
$$

In addition, for the local-similarity analysis of the buoyancy term, the local Grashof number will be set as follow:

$$
G r_{x, f}=\frac{g \beta\left(t_{w}-t_{\infty}\right)}{v_{f}^{2}}
$$

It is indicated that the independent coordinate variable $\eta$ and $\mathrm{x}$ related to the supposed similarity variables $W_{x}(\eta, x)$, $W_{y}(\eta, x)$, and $\theta(\eta, x)$ are taken to express the localnsimilarity issue, and the subscript $\mathrm{f}$ denotes the reference temperature is average temperature $t_{f}=\frac{t_{w}+t_{\infty}}{2}$.

\section{Local-Similarity Transformation of the Governing Equations}

For local-similarity analysis on the supposed dimensionless coordinate variable $\eta$ for the governing partial differential equations (1) to (3) of laminar free/forced mixed convection, the following transformation will be done:

\subsection{Transformation of Eq.(1)}

With Eqs.(6) we have

$$
\frac{\partial w_{x}}{\partial x}=w_{x, \infty}\left(\frac{\partial W_{x}(\eta, x)}{\partial \eta} \frac{\partial \eta}{\partial x}\right)
$$

and with Eqs. (9) and (10) we have

$$
\frac{\partial \eta}{\partial x}=-\frac{1}{2} y\left(\frac{1}{2} \frac{w_{x, \infty}}{v_{f}}\right)^{1 / 2} x^{-3 / 2}=-\frac{1}{2} \eta x^{-1}
$$

Then,

$$
\frac{\partial w_{x}}{\partial x}=-\frac{1}{2} w_{x, \infty} \eta x^{-1} \frac{\partial W_{x}(\eta, x)}{\partial \eta}
$$

With Eq. (7) we have

$$
\frac{\partial w_{y}}{\partial y}=w_{x, \infty}\left(\frac{1}{2} \operatorname{Re}_{x}\right)^{-1 / 2}\left(\frac{\partial W_{y}(\eta, x)}{\partial \eta} \frac{\partial \eta}{\partial y}\right)
$$

Where

$$
\begin{gathered}
\frac{\partial \eta}{\partial y}=x^{-1}\left(\frac{1}{2} \operatorname{Re}_{x, \infty}\right)^{1 / 2}, \text { then, } \\
\frac{\partial w_{y}}{\partial y}=w_{x, \infty}\left(\frac{1}{2} \operatorname{Re}_{x, \infty}\right)^{-1 / 2} \frac{\partial W_{y}(\eta, x)}{\partial \eta} x^{-1}\left(\frac{1}{2} \operatorname{Re}_{x, \infty}\right)^{1 / 2} \\
=w_{x, \infty} \frac{\partial W_{y}(\eta, x)}{\partial \eta} x^{-1}
\end{gathered}
$$

Therefore, Eq. (1) is transformed to

$$
\begin{gathered}
-\frac{1}{2} w_{x, \infty} \eta x^{-1} \frac{\partial W_{x}(\eta, x)}{\partial \eta}+w_{x, \infty} \frac{\partial W_{y}(\eta, x)}{\partial \eta} x^{-1}=0 \\
-\frac{1}{2} w_{x, \infty} \eta x^{-1} \frac{\partial W_{x}(\eta, x)}{\partial \eta}+w_{x, \infty} \frac{\partial W_{y}(\eta, x)}{\partial \eta} x^{-1}=0
\end{gathered}
$$

i. e.

$$
-\eta \frac{\partial W_{x}(\eta, x)}{\partial \eta}+2 \frac{\partial W_{y}(\eta, x)}{\partial \eta}=0
$$

\subsection{Transformation of Eq. (2)}

With Eqs. (6) and (10) we have

$$
\begin{gathered}
\frac{\partial w_{x}}{\partial y}=w_{x, \infty}\left[\frac{\partial W_{x}(\eta, x)}{\partial \eta} \frac{\partial \eta}{\partial y}\right]=w_{x, \infty} \frac{\partial W_{x}(\eta, x)}{\partial \eta} x^{-1}\left(\frac{1}{2} \operatorname{Re}_{x, \infty}\right)^{1 / 2} \\
\frac{\partial^{2} w_{x}}{\partial y^{2}}=w_{x, \infty} \frac{\partial^{2} W_{x}(\eta, x)}{\partial \eta^{2}} x^{-1}\left(\frac{1}{2} \operatorname{Re}_{x, \infty}\right)^{1 / 2} \frac{\partial \eta}{\partial y} \\
=w_{x, \infty} \frac{\partial^{2} W_{x}(\eta, x)}{\partial \eta^{2}} x^{-2}\left(\frac{1}{2} \operatorname{Re}_{x, \infty}\right)
\end{gathered}
$$

Then, Eq. (2) is changed to

$$
\begin{aligned}
& \mathrm{w}_{\mathrm{x}, \infty} \mathrm{w}_{\mathrm{x}}(\eta, \mathrm{x})\left[-\frac{1}{2} \mathrm{w}_{\mathrm{x}, \infty} \eta \mathrm{x}^{-1} \frac{\partial \mathrm{w}_{\mathrm{x}}(\eta, \mathrm{x})}{\partial \eta}\right] \\
& +\mathrm{w}_{\mathrm{x}, \infty}\left(\frac{1}{2} \operatorname{Re}_{\mathrm{x}}\right)^{-1 / 2} \mathrm{~W}_{\mathrm{y}}(\eta, \mathrm{x}) \mathrm{w}_{\mathrm{x}, \infty} \frac{\partial \mathrm{w}_{\mathrm{x}}(\eta, \mathrm{x})}{\partial \eta} \mathrm{x}^{-1}\left(\frac{1}{2} \operatorname{Re}_{\mathrm{x}, \infty}\right)^{1 / 2} \\
& =\mathrm{v}_{\mathrm{f}} \mathrm{w}_{\mathrm{x}, \infty} \frac{\partial^{2} \mathrm{w}_{\mathrm{x}}(\eta, \mathrm{x})}{\partial \eta^{2}} \mathrm{x}^{-2}\left(\frac{1}{2} \operatorname{Re}_{\mathrm{x}, \infty}\right)+\mathrm{g} \beta\left(\mathrm{t}-\mathrm{t}_{\infty}\right)
\end{aligned}
$$

The above eq. should be

$$
\begin{aligned}
& \mathrm{w}_{\mathrm{x}, \infty} \mathrm{w}_{\mathrm{x}}(\eta, \mathrm{x})\left[-\frac{1}{2} \mathrm{w}_{\mathrm{x}, \infty} \eta \mathrm{x}^{-1} \frac{\partial \mathrm{w}_{\mathrm{x}}(\eta, \mathrm{x})}{\partial \eta}\right] \\
& +\mathrm{w}_{\mathrm{x}, \infty}\left(\frac{1}{2} \operatorname{Re}_{\mathrm{x}, \infty}\right)^{-1 / 2} \mathrm{w}_{\mathrm{y}}(\eta, \mathrm{x}) \mathrm{w}_{\mathrm{x}, \infty} \frac{\partial \mathrm{w}_{\mathrm{x}}(\eta, \mathrm{x})}{\partial \eta} \mathrm{x}^{-1}\left(\frac{1}{2} \operatorname{Re}_{\mathrm{x}, \infty}\right)^{1 / 2} \\
& =v_{\mathrm{f}} \mathrm{w}_{\mathrm{x}, \infty} \frac{\partial^{2} \mathrm{~W}_{\mathrm{x}}(\eta, \mathrm{x})}{\partial \eta^{2}} \mathrm{x}^{-2}\left(\frac{1}{2} \operatorname{Re}_{\mathrm{x}, \infty}\right)+\mathrm{g} \beta\left(\mathrm{t}-\mathrm{t}_{\infty}\right)
\end{aligned}
$$

i.e.

$$
\begin{aligned}
& \mathrm{w}_{\mathrm{x}, \infty} \mathrm{W}_{\mathrm{x}}(\eta, \mathrm{x})\left[-\frac{1}{2} \mathrm{w}_{\mathrm{x}, \infty} \eta \mathrm{x}^{-1} \frac{\partial \mathrm{W}_{\mathrm{x}}(\eta, \mathrm{x})}{\partial \eta}\right] \\
& +\mathrm{w}_{\mathrm{x}, \infty} \mathrm{W}_{\mathrm{y}}(\eta, \mathrm{x}) \mathrm{w}_{\mathrm{x}, \infty} \frac{\partial \mathrm{W}_{\mathrm{x}}(\eta, \mathrm{x})}{\partial \eta} \mathrm{x}^{-1} \\
& =\mathrm{v}_{\mathrm{f}} \mathrm{w}_{\mathrm{x}, \infty} \frac{\partial^{2} \mathrm{~W}_{\mathrm{x}}(\eta, \mathrm{x})}{\partial \eta^{2}} \mathrm{x}^{-2}\left(\frac{1}{2} \operatorname{Re}_{\mathrm{x}, \infty}\right)+\mathrm{g} \beta\left(\mathrm{t}-\mathrm{t}_{\infty}\right)
\end{aligned}
$$

The above equation is divided by $\frac{1}{2} x^{-1} w_{x, \infty}{ }^{2}$, and changed to 


$$
\begin{aligned}
& {\left[\mathrm{W}_{\mathrm{x}}(\eta, \mathrm{x})\left[-\eta \frac{\partial \mathrm{W}_{\mathrm{x}}(\eta, \mathrm{x})}{\partial \eta}\right]+2 \mathrm{~W}_{\mathrm{y}}(\eta, \mathrm{x}) \frac{\partial \mathrm{W}_{\mathrm{x}}(\eta, \mathrm{x})}{\partial \eta}\right]} \\
& =v_{\mathrm{f}} \frac{\partial^{2} \mathrm{~W}_{\mathrm{x}}(\eta, \mathrm{x})}{\partial \eta^{2}}\left(\frac{1}{v_{\mathrm{f}}}\right)+2 \mathrm{~g} \beta\left(\mathrm{t}-\mathrm{t}_{\infty}\right) \frac{\mathrm{x}}{\mathrm{w}_{\mathrm{x}, \infty}{ }^{2}}
\end{aligned}
$$

The above equation is changed equivalently to

$$
\left[W_{x}(\eta, x)\left(-\eta \frac{\partial W_{x}(\eta, x)}{\partial \eta}\right)+2 W_{y}(\eta, x) \frac{d W_{x}(\eta, x)}{\partial \eta}\right]=\frac{\partial^{2} W_{x}(\eta, x)}{\partial \eta^{2}}+\frac{t-t_{\infty}}{t_{w}-t_{\infty}} 2 \frac{g \beta\left(t_{w}-t_{\infty}\right) x^{3}}{v_{f}{ }^{2}} \operatorname{Re}_{x, f}^{-2}
$$

i.e.

$$
\begin{aligned}
& {\left[\mathrm{W}_{\mathrm{x}}(\eta, \mathrm{x})\left(-\eta \frac{\partial \mathrm{W}_{\mathrm{x}}(\eta, \mathrm{x})}{\partial \eta}\right)+2 \mathrm{~W}_{\mathrm{y}}(\eta, \mathrm{x}) \frac{\partial \mathrm{W}_{\mathrm{x}}(\eta, \mathrm{x})}{\partial \eta}\right]} \\
& =\frac{\partial^{2} \mathrm{~W}_{\mathrm{x}}(\eta, \mathrm{x})}{\partial \eta^{2}}+2 \theta(\eta, \mathrm{x}) \cdot \mathrm{Gr}_{\mathrm{x}, \mathrm{f}} \mathrm{Re}_{\mathrm{x}, \mathrm{f}}{ }^{-2}
\end{aligned}
$$

or

$$
\left.\left[-\eta W_{x}(\eta, x)+2 W_{y}(\eta, x)\right] \frac{\partial W_{x}(\eta, x)}{\partial \eta}\right]=\frac{\partial^{2} W_{x}(\eta, x)}{\partial \eta^{2}}+2 \theta(\eta, x) \cdot M c
$$

where

$$
M c=G r_{x, f} \operatorname{Re}_{x, f}{ }^{-2} \text { is Richardson number or called mixed }
$$
convection parameter. It demonstrates the effective rate of the free convection in the mixed convection. Theoretically, the value for the mixed convection parameter Mc can be in a large range $-\infty<M c<+\infty$. The free/forced mixed convection is divided to two types, respectively for positive (adding) and negative (opposing) flows. The former flow is corresponding to $M c>0$, and the latter flow is corresponding to $M c<0$. Obviously, $M c=0$ and $M c \rightarrow \pm \infty$ are corresponding to net forced convection and free convection respectively.

\subsection{Transformation of Eq. (3)}

With Eq. (8) we have

$$
\frac{\partial t}{\partial x}=\left(t_{w}-t_{\infty}\right) \frac{\partial \theta(\eta, x)}{\partial \eta} \frac{\partial \eta}{\partial x}
$$

Therefore,

$$
\begin{gathered}
\frac{\partial t}{\partial x}=\left(t_{w}-t_{\infty}\right) \frac{\partial \theta(\eta, x)}{\partial \eta}\left(-\frac{1}{2} \eta x^{-1}\right) \\
=\left(t_{w}-t_{\infty}\right)\left(-\frac{1}{2} \eta x^{-1}\right) \frac{\partial \theta(\eta, x)}{\partial \eta}
\end{gathered}
$$

With Eq. (8) we have

$$
\frac{\partial t}{\partial y}=\left(t_{w}-t_{\infty}\right) \frac{\partial \theta(\eta, x)}{\partial \eta} \frac{\partial \eta}{\partial y}
$$

Therefore,

$$
\frac{\partial t}{\partial y}=\left(t_{w}-t_{\infty}\right) \frac{\partial \theta(\eta, x)}{\partial \eta} x^{-1}\left(\frac{1}{2} \operatorname{Re}_{x, \infty}\right)^{1 / 2}
$$

$$
\begin{aligned}
& {\left[\mathrm{W}_{\mathrm{x}}(\eta, \mathrm{x})\left(-\eta \frac{\partial \mathrm{W}_{\mathrm{x}}(\eta, \mathrm{x})}{\partial \eta}\right)+2 \mathrm{~W}_{\mathrm{y}}(\eta, \mathrm{x}) \frac{\partial \mathrm{W}_{\mathrm{x}}(\eta, \mathrm{x})}{\partial \eta}\right]} \\
& =\frac{\partial^{2} \mathrm{~W}_{\mathrm{x}}(\eta, \mathrm{x})}{\partial \eta^{2}}+2 \frac{\mathrm{g} \beta\left(\mathrm{t}-\mathrm{t}_{\infty}\right) \mathrm{x}^{3}}{v_{\mathrm{f}}^{2}} \frac{\mathrm{v}_{\mathrm{f}}{ }^{2}}{\mathrm{w}_{\mathrm{x}, \infty}{ }^{2} \mathrm{x}^{2}}
\end{aligned}
$$

The above equation is further equivalently changed to

$$
\frac{\partial^{2} t}{\partial y^{2}}=x^{-2}\left(\frac{1}{2} \operatorname{Re}_{x, \infty}\right)\left(t_{w}-t_{\infty}\right) \frac{\partial \theta^{2}(\eta, x)}{\partial \eta^{2}}
$$

Then, Eq.(3) is changed to

$$
\begin{aligned}
& \mathrm{w}_{\mathrm{x}, \infty} \mathrm{W}_{\mathrm{x}}(\eta, \mathrm{x})\left(\mathrm{t}_{\mathrm{w}}-\mathrm{t}_{\infty}\right)\left[-\frac{1}{2} \eta \mathrm{x}^{-1} \frac{\partial \theta(\eta, \mathrm{x})}{\partial \eta}\right] \\
& +\mathrm{w}_{\mathrm{x}, \infty}\left(\frac{1}{2} \operatorname{Re}_{\mathrm{x}}\right)^{-1 / 2} \mathrm{w}_{\mathrm{y}}(\eta, \mathrm{x})\left(\mathrm{t}_{\mathrm{w}}-\mathrm{t}_{\infty}\right) \frac{\partial \theta(\eta, \mathrm{x})}{\partial \eta} \mathrm{x}^{-1}\left(\frac{1}{2} \operatorname{Re}_{\mathrm{x}, \infty}\right)^{1 / 2} \\
& =\frac{\mathrm{v}_{\mathrm{f}}}{\operatorname{Pr}_{\mathrm{f}}} \mathrm{x}^{-2}\left(\frac{1}{2} \operatorname{Re}_{\mathrm{x}, \infty}\right)\left(\mathrm{t}_{\mathrm{w}}-\mathrm{t}_{\infty}\right) \frac{\partial^{2} \theta(\eta, \mathrm{x})}{\partial \eta^{2}}
\end{aligned}
$$

i.e.

$\mathrm{w}_{\mathrm{x}, \infty} \mathrm{W}_{\mathrm{x}}(\eta, \mathrm{x})\left(\mathrm{t}_{\mathrm{w}}-\mathrm{t}_{\infty}\right)\left[-\eta \mathrm{x}^{-1} \frac{\partial \theta(\eta, \mathrm{x})}{\partial \eta}\right]+2 \mathrm{w}_{\mathrm{x}, \infty} \mathrm{W}_{\mathrm{y}}(\eta, \mathrm{x})\left(\mathrm{t}_{\mathrm{w}}-\mathrm{t}_{\infty}\right) \frac{\partial \theta(\eta, \mathrm{x})}{\partial \eta} \mathrm{x}^{-1}$

$=\frac{v_{f}}{P_{f}} x^{-2}\left(\frac{x w_{x, \infty}}{v_{f}}\right)\left(t_{w}-t_{\infty}\right) \frac{\partial^{2} \theta(\eta, x)}{\partial \eta^{2}}$

The above equation is divided by $x^{-1} w_{x, \infty}\left(t_{w}-t_{\infty}\right)$, and transformed to

$$
W_{x}(\eta, x)\left[-\eta \frac{\partial \theta(\eta, x)}{\partial \eta}\right]+2 W_{y}(\eta, x) \frac{\partial \theta(\eta, x)}{\partial \eta}=\frac{1}{\operatorname{Pr}_{f}} \frac{\partial^{2} \theta(\eta, x)}{\partial \eta^{2}}
$$

or

$$
\left[-\eta W_{x}(\eta, x)+2 W_{y}(\eta, x)\right] \frac{\partial \theta(\eta, x)}{\partial \eta}=\frac{1}{\operatorname{Pr}_{f}} \frac{\partial^{2} \theta(\eta, x)}{\partial \eta^{2}}
$$

Then, with the local-summary transformation, Eqs. (1) to (3) are transformed to the following equivalent governing ordinary differential equations:

$$
-\eta \frac{\partial W_{x}(\eta, x)}{\partial \eta}+2 \frac{\partial W_{y}(\eta, x)}{\partial \eta}=0
$$

$\left.\left[-\eta W_{x}(\eta, x)+2 W_{y}(\eta, x)\right] \frac{\partial W_{x}(\eta, x)}{\partial \eta}\right]=\frac{\partial^{2} W_{x}(\eta, x)}{\partial \eta^{2}}+2 \theta(\eta, x) \cdot M c$

$$
\left[-\eta W_{x}(\eta, x)+2 W_{y}(\eta, x)\right] \frac{\partial \theta(\eta, x)}{\partial \eta}=\frac{1}{\operatorname{Pr}_{f}} \frac{\partial^{2} \theta(\eta, x)}{\partial \eta^{2}}
$$

with the following dimensionless equations on the boundary layer conditions:

$$
\eta=0: W_{x}(\eta, x)=0, W_{y}(\eta, x)=0, \theta(\eta, x)=1
$$




$$
\eta \rightarrow \infty: W_{x}(\eta, x)=1, \theta(\eta, x)=0
$$

\section{Rewriting the Second Independent Coordinate Variable}

From the defined equation of the mixed convection parameter $\mathrm{Mc}$, it is seen that the independent coordinate variable $\mathrm{x}$ is included in the mixed convection parameter Mc. From the transformed governing equations (12) to (14), it is found that the supposed second coordinate variable $\mathrm{x}$ exists in the transformed governing equations only in form of the mixed convection parameter Mc. Then, the mixed parameter $\mathrm{Mc}$ is reasonably taken as the second independent coordinate variable to replace the independent coordinate variable $\mathrm{x}$. In this case, the transformed dimensionless governing Eqs.(12) to (14) are equivalent to the following ones respectively

$$
\begin{gathered}
-\eta \frac{\partial W_{x}(\eta, M c)}{\partial \eta}+2 \frac{\partial W_{y}(\eta, M c)}{\partial \eta}=0 \\
\left.\left[-\eta \mathrm{W}_{\mathrm{x}}(\eta, \mathrm{Mc})+2 \mathrm{~W}_{\mathrm{y}}(\eta, \mathrm{Mc})\right] \frac{\partial \mathrm{W}_{\mathrm{x}}(\eta, \mathrm{Mc})}{\partial \eta}\right] \\
=\frac{\partial^{2} \mathrm{~W}_{\mathrm{x}}(\eta, \mathrm{Mc})}{\partial \eta^{2}}+2 \theta(\eta, \mathrm{Mc}) \cdot \mathrm{Mc} \\
{\left[-\eta W_{x}(\eta, M c)+2 W_{y}(\eta, M c)\right] \frac{\partial \theta(\eta, M c)}{\partial \eta}=\frac{1}{\operatorname{Pr}_{f}} \frac{\partial^{2} \theta(\eta, M c)}{\partial \eta^{2}}}
\end{gathered}
$$

with the following equivalent dimensionless equations on the boundary conditions

$$
\begin{gathered}
\eta=0: W_{x}(\eta, M c)=0, W_{y}(\eta, M c)=0, \theta(\eta, M c)=1 \\
\eta \rightarrow \infty: W_{x}(\eta, M c)=1, \theta(\eta, M c)=0
\end{gathered}
$$

and the corresponding equivalent similarity variables $W_{x}(\eta, x), W_{y}(\eta, x)$ and $\theta(\eta, x)$ with the following relations:

$$
\begin{gathered}
w_{x}=w_{x, \infty} W_{x}(\eta, M c) \\
w_{y}=w_{x, \infty}\left(\frac{1}{2} \operatorname{Re}_{x}\right)^{-1 / 2} W_{y}(\eta, M c) \\
\theta(\eta, M c)=\frac{t-t_{\infty}}{t_{w}-t_{w}}
\end{gathered}
$$

\section{Numerical Results}

The governing dimensionless local-similarity equations $(12)^{*}$ to $(14)^{*}$ with their boundary condition equations $(15)^{*}$ and (16)* are solved by a shooting method with fifth-order Runge-Kutta integration. For solving the nonlinear problem, a variable mesh approach is applied to the numerical calculation programs. It can be seen that for ignoring the variable physical properties, the solutions of the dimensionless velocity components
$W_{x}(\eta, M c)$ and $W_{y}(\eta, M c)$ and the dimensionless temperature $\theta(\eta, M c)$ are dependent on Prandtl number $\operatorname{Pr}_{f}$ and mixed convection parameter Mc. The accurate numerical results of the velocity and temperature fields are obtained in the wide ranges of Prandtl number $\operatorname{Pr}_{f}\left(0.3 \leq \operatorname{Pr}_{f} \leq 20\right)$ and mixed parameter $\mathrm{Mc}(0 \leq \mathrm{Mc} \leq 10)$. Some of the selected numerical results for the dimensionless velocity component $W_{x}(\eta, M c)$ and temperature $\theta(\eta, M c)$ fields are plotted in Figs. 2 to 7 with variation of the dimensionless coordinate variable $\eta$.

It is seen that with increasing the Prandtl number, the velocity will decrease monotonically, and the velocity and temperature boundary layer thickness will decrease monotonically, too. In addition, with increasing the mixed convection parameter $\mathrm{Mc}$, the velocity will increase monotonically. However, the velocity and temperature boundary layer thickness will not obviously change with variation of the mixed convection parameter Mc.

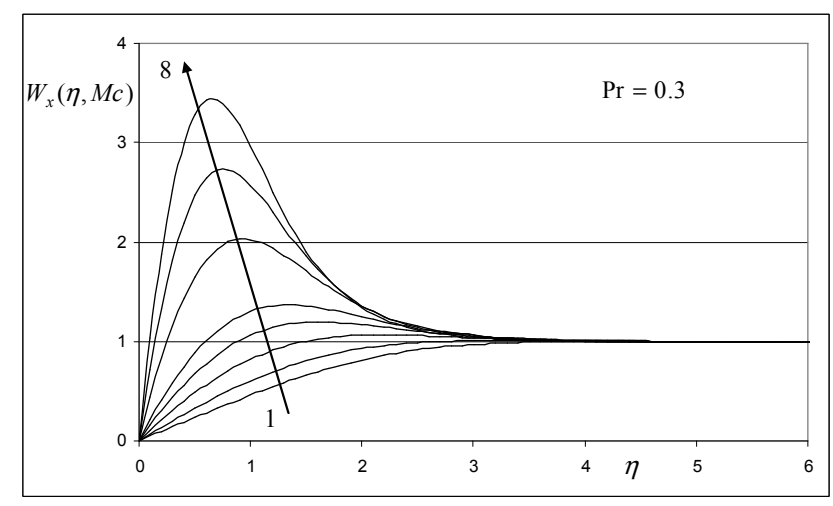

a

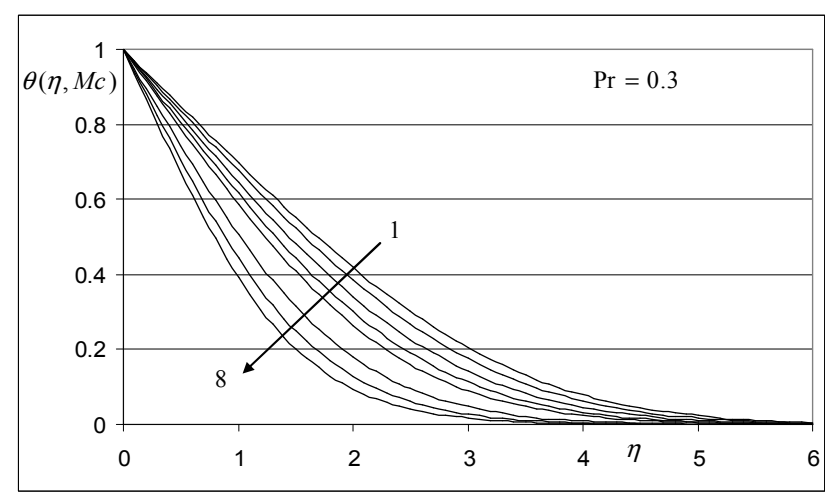

Note: Lines 1 to 8 denote $\mathrm{Mc}=0,0.1,0.3,0.6,1,3,6$ and 10 respectively

Fig. 2. Numerical results of (a) velocity component $W_{x}(\eta, M c)$ and (b) temperature $\theta(\eta, M c)$ profiles for laminar fixed convection with fluid for $P r=0.3$ on a vertical flat plate 


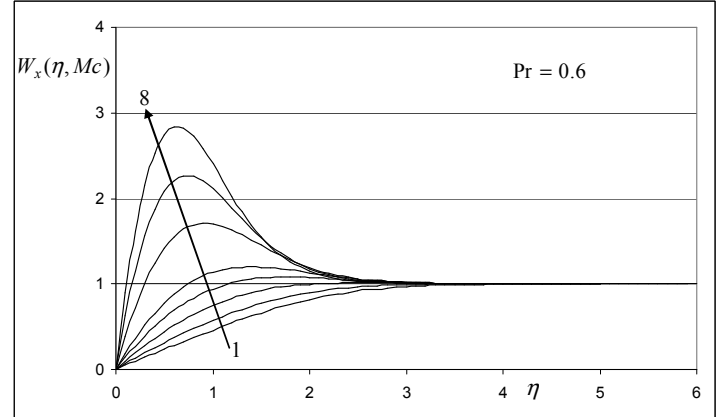

a

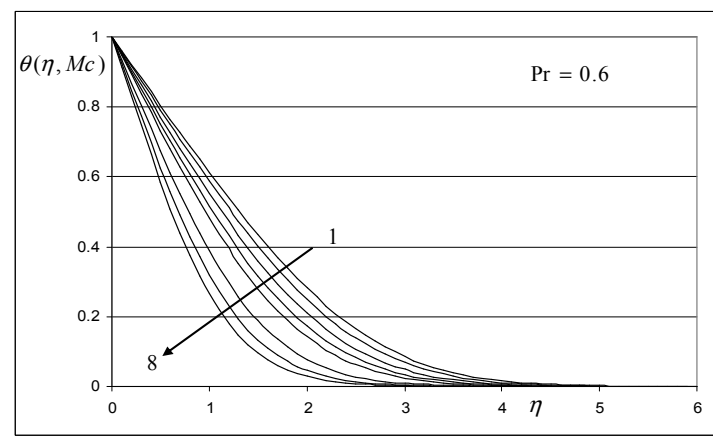

Note: Lines 1 to 8 denote $\mathrm{Mc}=0,0.1,0.3,0.6,1,3,6$ and 10 respectively

Fig. 3. Numerical results of (a) velocity component $W_{x}(\eta, M c)$ and (b) temperature $\theta(\eta, M c)$ profiles for laminar fixed convection with fluid for $P r=0.6$ on a vertical flat plate
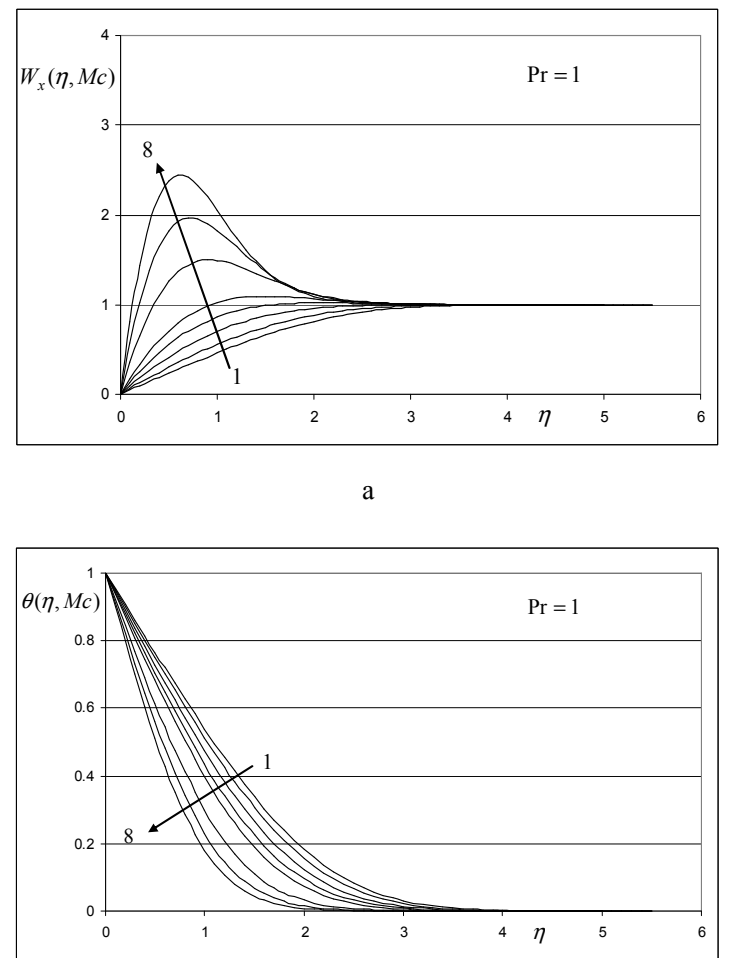

b

Note: Lines 1 to 8 denote $\mathrm{Mc}=0,0.1,0.3,0.6,1,3,6$ and 10 respectively

Fig. 4. Numerical results of (a) velocity component $W_{x}(\eta, M c)$ and (b) temperature $\theta(\eta, M c)$ profiles for laminar fixed convection with fluid for $P r=1.0$ on a vertical flat plate
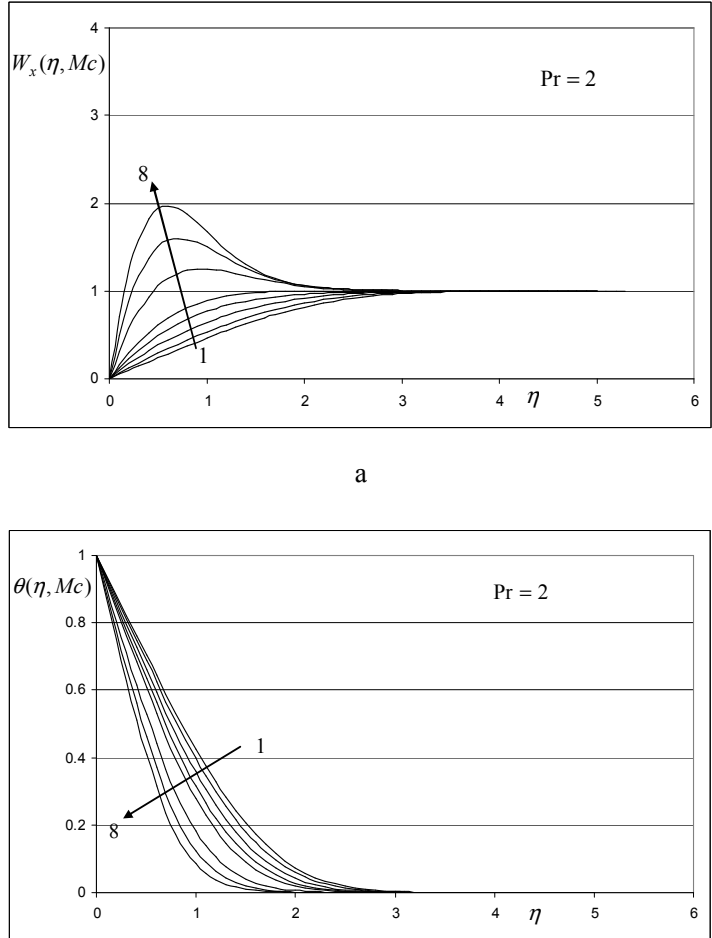

Note: Lines 1 to 8 denote $\mathrm{Mc}=0,0.1,0.3,0.6,1,3,6$ and 10 respectively

Fig. 5. Numerical results of (a) velocity component $W_{x}(\eta, M c)$ and (b) temperature $\theta(\eta, M c)$ profiles for laminar fixed convection with fluid for $P r=2.0$ on a vertical flat plate
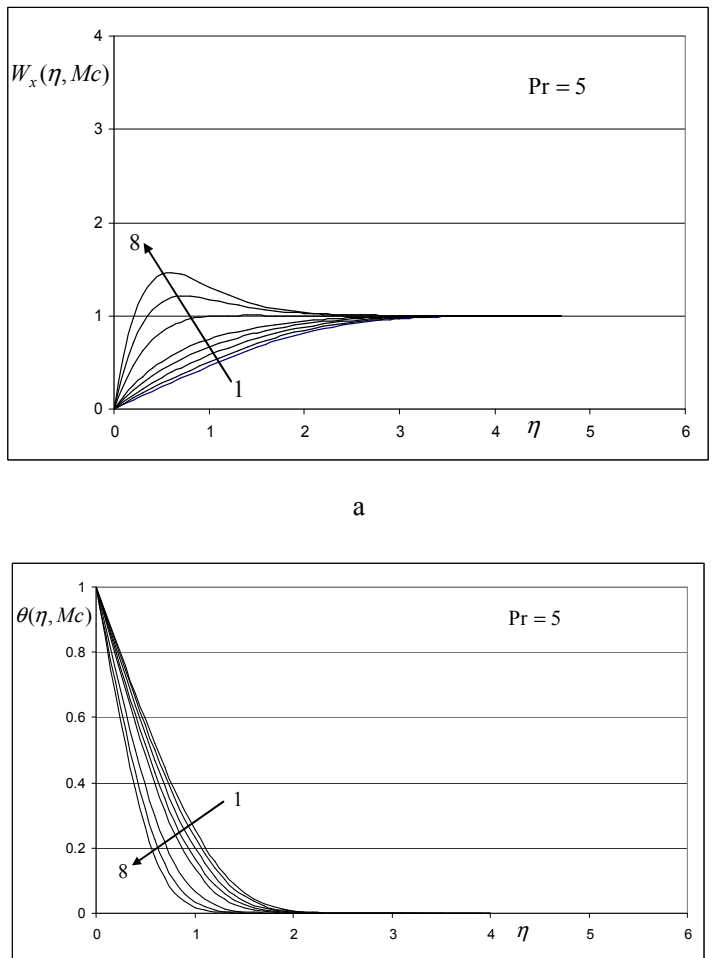

$\mathrm{b}$

Note: Lines 1 to 8 denote $\mathrm{Mc}=0,0.1,0.3,0.6,1,3,6$ and 10 respectively

Fig. 6. Numerical results of (a) velocity component $W_{x}(\eta, M c)$ and (b) temperature $\theta(\eta, M c)$ profiles for laminar fixed convection with fluid for $\operatorname{Pr}=5.0$ on a vertical flat plate 


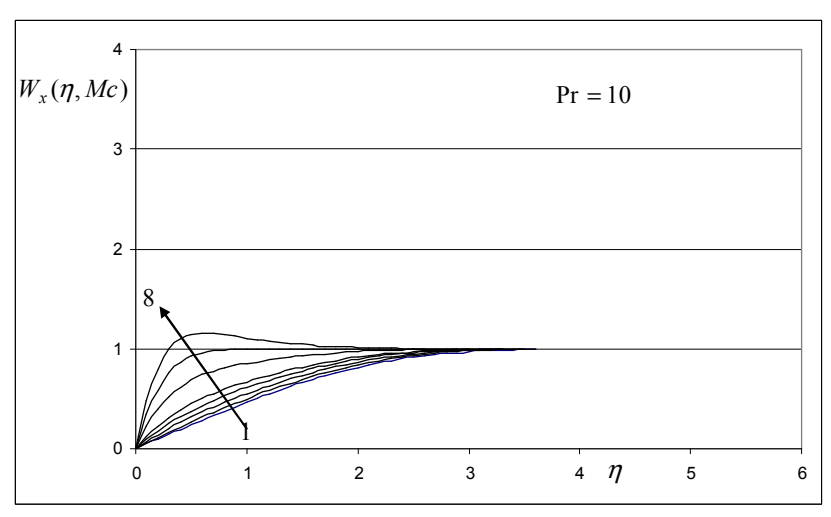

a

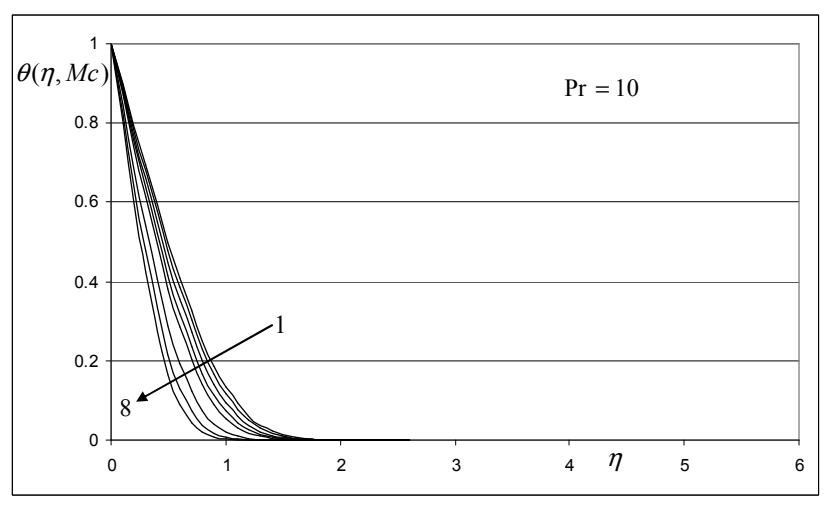

b

Note: Lines 1 to 8 denote $\mathrm{Mc}=0,0.1,0.3,0.6,1,3,6$ and 10 respectively

Fig. 7. Numerical results of (a) velocity component $W_{x}(\eta, M c)$ and (b) temperature $\theta(\eta, M c)$ profiles for laminar fixed convection with fluid for $\operatorname{Pr}=10.0$ on a vertical flat plate

\section{Skin-Friction Coefficient}

So far, the skin friction coefficient has been analyzed by means of Falkner-Skan type transformation for free/forced mixed convection. In the present work, we will analyze it based on the present new similarity analysis procedure. For this analysis, the velocity gradient at the wall is important characteristic of the solution, and the local skin-friction coefficient $C_{x, f}$ is a dimensionless measure of the shear stress at the wall, i.e.

$$
C_{x, f}=\frac{\tau_{w, x}}{\frac{1}{2} \rho_{f} w_{x, \infty}^{2}}=\frac{\mu_{f}\left(\frac{\partial w_{x}}{\partial y}\right)_{y=0}}{\frac{1}{2} \rho_{f} w_{x, \infty}^{2}}
$$

According to the related derivation in section 3, we have

$$
\left(\frac{\partial w_{x}}{\partial y}\right)_{y=0}=x^{-1}\left(\frac{1}{2} \operatorname{Re}_{x, f}\right)^{1 / 2} w_{x, \infty}\left(\frac{\partial W_{x}(\eta, M c)}{\partial \eta}\right)_{\eta=0}
$$

Therefore, the local skin-friction coefficient $C_{f, x}$ is expressed as

$$
\begin{aligned}
& C_{x, f}=\frac{\mu_{f} x^{-1}\left(\frac{1}{2} \operatorname{Re}_{x, f}\right)^{1 / 2} w_{x, \infty}\left(\frac{\partial W_{x}(\eta, M c)}{\partial \eta}\right)_{\eta=0}}{\frac{1}{2} \rho_{f} w_{x, \infty}^{2}} \\
& =\sqrt{2} \frac{v_{f}}{x w_{x, \infty}}\left(\operatorname{Re}_{x, f}\right)^{1 / 2}\left(\frac{\partial W_{x}(\eta, M c)}{\partial \eta}\right)_{\eta=0}
\end{aligned}
$$

i.e.

$$
C_{x, f}=\sqrt{2}\left(\operatorname{Re}_{x, f}\right)^{-1 / 2}\left(\frac{\partial W_{x}(\eta, M c)}{\partial \eta}\right)_{\eta=0}
$$

A system of the rigorous numerical solutions on the wall velocity gradient $\left(\frac{\partial W_{x}(\eta, M c)}{\partial \eta}\right)_{\eta=0}$ has been obtained numerically. The selected solutions of them are plotted in Fig. 8 with variation of Prandtl number $\operatorname{Pr}_{\mathrm{f}}$ and mixed convection parameter Mc. Then, it is seen that the velocity gradient on the wall, $\left(\frac{\partial W_{x}(\eta, M c)}{\partial \eta}\right)_{\eta=0}$ increases with increasing the mixed convection parameter $\mathrm{Mc}$, and decreases with increasing the Prandtl number $\operatorname{Pr}_{\mathrm{f}}$. In addition, with increasing the mixed convection parameter Mc, the velocity gradient on the wall, $\left(\frac{\partial W_{x}(\eta, M c)}{\partial \eta}\right)_{\eta=0}$ will decrease in an accelerative pace.

From Eq. (18) it is seen that the wall velocity gradient $\left(\frac{\partial W_{x}(\eta, M c)}{\partial \eta}\right)_{\eta=0}$ is the only one unknown variable for evaluation of the skin-friction coefficient.

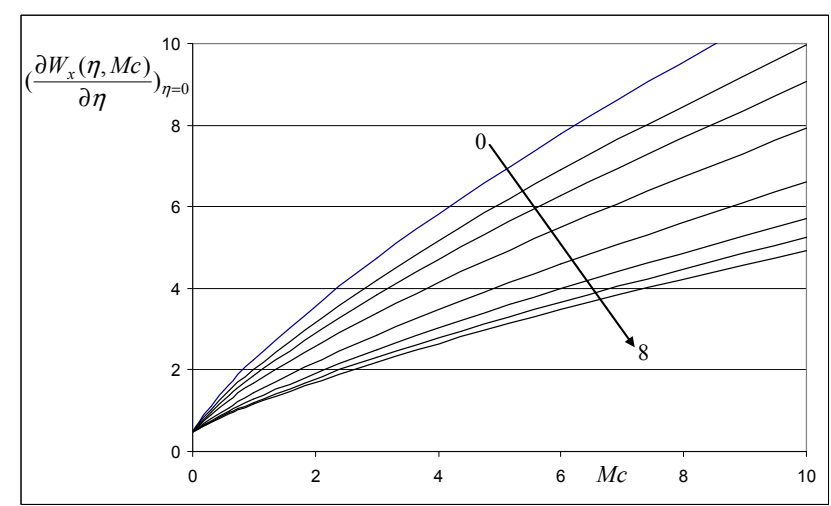

Fig. 8. Numerical results of velocity gradient on the plate surface, $\left(\frac{\partial W_{x}(\eta, M c)}{\partial \eta}\right)_{\eta=0}$ varying with Prandtl number, Pr and mixed convection parameter Mc (Lines 1 to 8 denote $\operatorname{Pr}_{\mathrm{f}}=0.3,0.6,1,2,5,10,15$ and 20 respectively).

\section{Heat Transfer}

\subsection{Theoretical Equations of heat transfer}

The local heat transfer rate $q_{x, f}$ at position x per unit area from the surface of the plate without consideration of 
variable physical properties can be calculated by Fourier's law as $q_{x, f}=-\lambda_{f}\left(\frac{\partial t}{\partial y}\right)_{y=0}$. The subscript $\mathrm{f}$ denotes the case that the boundary layer average temperature $t_{f}=\frac{t_{w}+t_{\infty}}{2}$ is taken as the reference temperature with ignoring the variable physical properties.

With Eqs. (8) and (10) we have

$$
q_{x, f}=-\lambda_{f}\left(t_{w}-t_{\infty}\right)\left(\frac{\partial \theta(\eta, M c)}{\partial \eta}\right)_{\eta=0} \frac{\partial \eta}{\partial y}
$$

where

$$
\frac{\partial \eta}{\partial y}=x^{-1}\left(\frac{1}{2} \operatorname{Re}_{x, \infty}\right)^{1 / 2}
$$

Then,

$$
q_{x, f}=\lambda_{f}\left(t_{w}-t_{\infty}\right)\left(\frac{1}{2} \operatorname{Re}_{x, f}\right)^{1 / 2} x^{-1}\left(-\frac{\partial \theta(\eta, M c)}{\partial \eta}\right)_{\eta=0}
$$

The local heat transfer coefficient $\alpha_{x, f}$, defined as $q_{x, f}=\alpha_{x, f}\left(t_{w}-t_{\infty}\right)$, will be given by

$$
\alpha_{x, f}=\lambda_{f}\left(\frac{1}{2} \operatorname{Re}_{x, f}\right)^{1 / 2} x^{-1}\left(-\frac{\partial \theta(\eta, M c)}{\partial \eta}\right)_{\eta=0}
$$

The local Nusselt number, defined by $N u_{x, f}=\frac{\alpha_{x, f} \cdot x}{\lambda_{f}}$, will be

$$
N u_{x, f}=\left(\frac{1}{2} \operatorname{Re}_{x, f}\right)^{1 / 2}\left(-\frac{\partial \theta(\eta, M c)}{\partial \eta}\right)_{\eta=0}
$$

Here, Equation on local Nusselt number(19 is heat transfer theoretical equation.

\subsection{Formulization of Dimensionless Wall Temperature Gradient}

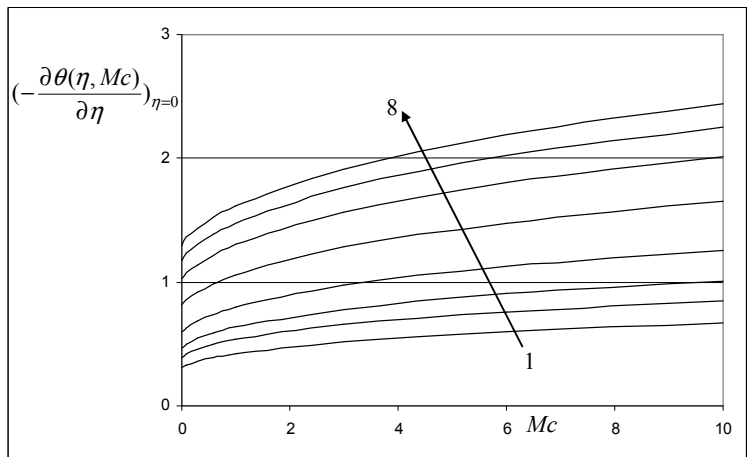

Fig. 9. Numerical results of wall temperature gradient on the plate surface, $\left(-\frac{\partial \theta(\eta, M c)}{\partial \eta}\right)_{\eta=0}$ varying with Prandtl number Pr and mixed convection parameter Mc (Lines 1 to 8 denote $P r=0.3,0.6,1,2,5,10,15$ and 20 respectively)
It is seen from the heat transfer theoretical equation (19) that the dimensionless temperature gradient $\left(-\frac{\partial \theta(\eta, M c)}{\partial \eta}\right)_{\eta=0}$ as the only one unknown variable dominates the prediction of mixed convection heat transfer. In this present work, a system of rigorous solutions on the dimensionless temperature gradient $\left(-\frac{\partial \theta(\eta, M c)}{\partial \eta}\right)_{\eta=0}$ have been obtained numerically, and their selected values are plotted in Fig. 9. It is seen that the wall temperature gradient $\left(-\frac{\partial \theta(\eta, M c)}{\partial \eta}\right)_{\eta=0}$ increases with increasing the mixed parameter $\mathrm{Mc}$, and increases with increasing the Prandtl number $\operatorname{Pr}_{\mathrm{f}}$.

The system of rigorous numerical solutions of the wall temperature gradient $\left(-\frac{\partial \theta(\eta, M c)}{\partial \eta}\right)_{\eta=0}$ are formulated by means of a curve-fitting approach, and the obtained formulated correlations are shown as follows with the wide ranges of Prandtl number between 0.3 and 20 and the mixed convection parameter Mc between 0 and 10:

$$
\left(-\frac{\partial \theta(\eta, M c)}{\partial \eta}\right)_{\eta=0}=a \operatorname{Pr}_{f}^{b} \quad(0.3 \leq \operatorname{Pr} \leq 20)
$$

where

$$
\begin{gathered}
\mathrm{a}=\frac{\left(-0.0002 \mathrm{M} c^{4}+0.0039 \mathrm{Mc} c^{3}-0.0262 \mathrm{Mc}^{2}+0.6179 \mathrm{Mc}+0.4699\right)}{(1+\mathrm{Mc})^{0.75}} \\
(0 \leq M c \leq 10) \\
\mathrm{b}=\frac{\left(0.00009 \mathrm{Mc}^{4}-0.0018 \mathrm{Mc}^{3}+0.0117 \mathrm{Mc}^{2}+0.2771 \mathrm{Mc}+0.3433\right)}{1+\mathrm{Mc}} \\
(0 \leq M c \leq 10)
\end{gathered}
$$

Here, Eqs.(19) to (22) are heat transfer correlations of laminar mixed convection on a vertical flat plate.

If $\mathrm{Mc}=0$, Eqs. (21) to (23) will be attributed to the forced convection issue as follows:

$$
\left(-\frac{\partial \theta(\eta, M c)}{\partial \eta}\right)_{\eta=0}=0.4699 \operatorname{Pr}_{f}^{0.3433}
$$

It is seen that Eq. (20)* is equivalent to Eq. (5.12) derived in [26] for laminar forced convection, and obviously is corresponding to well-known Pohlhausen equation [26]. Obviously, forced convection is only a special case of mixed convection.

\section{Conclusions}

In this work, the heat transfer correlations of laminar mixed convection on a vertical flat plate are obtained by combination of the theoretical heat transfer equations with the formulization correlations based on the system of 
accurate numerical solutions of dimensionless temperature gradient, which contains the following three novel approaches:

First, a new local-similarity analysis method is provided for extensive studies on laminar mixed convection to replace the traditional Falkner-Skan type transformation.

Second, a novel governing local-similarity model is derived based the above local-similarity analysis method for extensive study on laminar mixed convection. This model is easier to be derived and can be more conveniently applied than that based on the Falkner-Skan type transformation.

Third, the novel correlations of heat transfer are devoted for heat transfer application of laminar mixed convection. The correlations have so wide coverage berceuse with the ranges of Prandtl number from 0.3 to 20 and mixed convection parameter from 0 to 10 they are suitable for prediction of heat transfer of mixed convection of all gases and some important liquids including water. In additions, the heat transfer correlations are produced rigorously because they are based on combination of heat transfer theoretical equation with formulization correlations created according to a system of reliable numerical solutions of dimensionless temperature gradient.

The present work provides a foundation on theoretical methodology and governing mathematical model for our further investigation of challenge issue on mixed convection heat transfer with consideration of coupled effect of variable physical properties.

\section{Nomenclature}

\begin{tabular}{|c|c|}
\hline $\mathrm{b}$ & exponent in equation \\
\hline$C_{f, x}$ & local skin-friction coefficient \\
\hline $\begin{array}{l}\mathrm{g} \\
G r_{x, f}\end{array}$ & $\begin{array}{l}\text { Gravity acceleration, } m / s^{2} \\
\text { local Grashof number, } G r_{x, f}\end{array}$ \\
\hline Mc & $\begin{array}{l}\text { Mixed convection } \quad \text { parameter, } \\
M c=G r_{x, f} \operatorname{Re}_{x, f}^{-2}\end{array}$ \\
\hline$N u_{x, f}$ & local Nusselt number \\
\hline $\operatorname{Pr}$ & Prandtl number \\
\hline $\mathrm{Re}_{x, f}$ & local Reynolds number \\
\hline $\mathrm{s}$ & width, m \\
\hline $\mathrm{t}$ & temperature, ${ }^{o} \mathrm{C}$ \\
\hline$t_{w}$ & wall temperature, ${ }^{o} \mathrm{C}$ \\
\hline$t_{\infty}$ & bulk temperature, ${ }^{o} \mathrm{C}$ \\
\hline$t_{f}$ & mean temperature, ${ }^{\circ} \mathrm{C}$ \\
\hline $\begin{array}{l}\mathrm{x}, \mathrm{y} \\
w_{x}, w_{y}\end{array}$ & $\begin{array}{l}\text { coordinate variables, } \mathrm{m} \\
\text { velocity components in } \mathrm{x} \text { and } \mathrm{y} \\
\text { directions, respectively, } \mathrm{m} / \mathrm{s} \\
\text { dimensionless similarity variables on }\end{array}$ \\
\hline$w_{x}, w_{y}$ & $\begin{array}{l}\text { velocity components } w_{x}, w_{y}, \\
\text { respectively }\end{array}$ \\
\hline
\end{tabular}

$\begin{array}{ll}w_{x, \infty} & \text { velocity of bulk flow, } \mathrm{m} / \mathrm{s} \\ \eta & \text { dimensionless coordinate variable } \\ \beta & \text { expansion coefficient, } 1 / \mathrm{K} \\ v & \text { kinetic viscosity, } \mathrm{m}^{2} / \mathrm{s} \\ \theta & \text { dimensionless temperature variable } \\ \tau_{w, x} & \text { local wall skin shear force, } N / \mathrm{m}^{2} \\ \left(-\frac{\partial \theta(\eta, M c)}{\partial \eta}\right)_{\eta=0} & \text { dimensionless temperature gradient } \\ \text { Subscript } & \text { on the wall } \\ \mathrm{f} & \text { average value } \\ \mathrm{w} & \text { wall surface } \\ \infty & \text { far from the wall surface }\end{array}$

\section{References}

[1] B. Gebhart and Y. Jaluria, Mahajan RL, Sammakia B. Buoyancy-induced flows and transfort. Hemisphere; 1988.

[2] A. Bejan, Convective heat transfer. Willey Inter Science; 1994.

[3] I. Pop and D.B. Ingham, Convective heat transfer: mathematical and computational odelling of viscous fluids and porous media. Elsevier UK, 2001.

[4] A. Acrivos, Combined laminar free and forced convection heat transfer in external flows, AIChE J. 4, 1958, 285-289

[5] E.M. Sparrow, R. Eichhorn, J.L Gregg, Combined forced and free convection in a boundary layer flow. Phys. of Fluids 2 (1959) 319-328

[6] A.A. Szewcyk, "Combined Forced and Free Convection Laminar Flow," Jour. Heat Transfer, Trans. ASME, Series C, Vol. 86, No. 4, November 1964, pp. 501-507.

[7] P.H. Oosthuizen and R. Hart, A numerical study of laminar combined convection flow over flat plates. J. Heat Transfer 95 (1973) 6063

[8] P. Cheng, Combined free and forced boundary layer flows about inclined surfaces in a porous medium, Int. J. Neat Mass Transfer 20, 807-814 (1977).

[9] T.S. Chen and C.F. Yuh, A. Moutsoglou, Combined heat and mass transfer in mixed convection along vertical and inclined plates, International Journal of Heat and Mass transfer, Volume 23, Issue 4, 1980, Pages 527-537

[10] M.S. Raju, X.Q. Liu and C.K. Law, A formulation of combined forced and free convection past horizontal and vertical surfaces. Int. J. Heat Mass Transfer 27 (1984) 22152224

[11] T.S. Chen and B.F. Armaly, N. Ramachandran, Correlations for laminar mixed convection flows on vertical, inclined, and horizontal flat plates, ASME J. Heat Transfer 108 (1986) 835-840.

[12] L.S. Yao, Two-dimensional mixed convection along a flat plate, ASME J. Heat Transfer. 109 (1987) 440-445.

[13] J.C. Hsieh, T.S. Chen and B.F. Armaly, "Non-similarity solutions for mixed convection from vertical surfaces in porous media: variable surface temperature or heat flux", International Journal of Heat and Mass Transfer, Vol. 36, 1993, pp. 1485-93 
[14] N. G. Kafoussias and E. W. Williams, The effect of temperature-dependent viscosity on free-forced convective laminar boundary layer flow past a vertical isothermal flat plate, Acta Mechanica Volume 110, Numbers 1-4, 123-137, 1995

[15] C.H. Chen, Laminar mixed convection adjacent to vertical, continuously stretching sheets, Heat and Mass Transfer, Volume 33, Issue 5/6, pp. 471-476 (1998).

[16] S.D. Harris, D.B. Ingham and I. Pop, Unsteady mixed convection boundary-layer flow on a vertical surface in a porous medium, Int. J. Heat Mass Transfer J. Heat and Mass Transfer, 42: 357 - 372, 1999

[17] M. A. Hossain and M. S. Munir, Mixed convection flow from a vertical flat plate with temperature dependent viscosity, Int. J. Therm. Sci. (2000) 39, 173-183

[18] J.H. Merkin and I. Pop, 2002. Mixed convection along a vertical surface: similarity solutions for uniform flow, Fluid Dyn. Res. 30, 233-250.

[19] H. Steinr'uck, About the physical relevance of similarity solutions of the boundary-layer flow equations describing mixed convection flow along a vertical plate, Fluid Dynamics Research 32 (2003) 1-13
[20] Sami A. Al-Sanea, Mixed convection heat transfer along a continuously moving heated vertical plate with suction or injection, International Journal of Heat and Mass Transfer 47 (2004) 1445-1465

[21] M.E. Ali, The effect of variable viscosity on mixed convection heat transfer along a vertical moving surface, Int. J. Therm. Sci. 45 (2006) 60-69

[22] Aydin O, Kaya A (2007) Mixed convection of a viscous dissipating fluid about a vertical flat plate. Appl Math Model $31: 843-853$

[23] P. Rana, R. Bhargava, Numerical study of heat transfer enhancement in mixed convection flow along a vertical plate with heat source/sink utilizing nanofluids, Commun Nonlinear Sci Numer Simulat 16 (2011) 4318-4334

[24] Devarapu Anilkumar, Nonsimilar solutions from a moving vertical, /Commun Nonlinear Sci Numer Simulat 16 (2011) $3147-3157$

[25] D.Y. Shang, "Theory of heat transfer with forced convection film flows", Springer-Verlag, Berlin, Heldberg2011

[26] E. Pohlhausen, Der Warmeaustausch zwischen festen Korpern und Flussigkeiten mit kleiner Reiburg und kleiner Warmeleitung. Z. Angew. Math. Mech.1, 115-121, 1921. 